\title{
Ethnic Identity of Older Chinese in Canada
}

\author{
Daniel W. L. Lai
}

Published online: 27 December 2011

C The Author(s) 2011. This article is published with open access at Springerlink.com

\begin{abstract}
In Canada's multicultural society, ethnic identity is important to the elderly and can influence areas such as access to services, health promotion and care. Often, the complex nature of ethnic identity is underestimated when looking at cultural groups. This study aims to: (a) validate the factor structure of a Chinese ethnic identity measure for older Chinese in Canada, (b) examine the level of ethnic identity of the participants, and (c) examine the correlates of ethnic identity in these older individuals. Using data from a large, national research project on the elderly Chinese in Canada, this study analyzed the results gathered from a total of 2,272 participants. Principal component analysis, maximum-likelihood confirmatory factor analysis, and multiple regression analysis were performed. The results indicated that ethnic identity of the older Chinese is a multi-dimensional construct made up of three factors: (a) culture related activities, (b) community ties, (c) linkage with country of origin, and (d) cultural identification. The findings have provided a better understanding of how ethnic identity can be measured among the aging Chinese population in Canada.
\end{abstract}

Keywords Chinese elderly $\cdot$ Immigrants $\cdot$ Ethnic identity

\section{Introduction}

Cultural diversity and ethnic identity

Canada is a country where people from all over the world have come to call it their home.

According to the 2006 Census, immigrants accounted for $19.8 \%$ of the Canadian population, the highest proportion in 75 years (Statistics Canada 2007). In the last two decades, Canada has witnessed changes in the sources of immigrants, from mainly European countries in the past to predominantly Asian, African, and East European countries at this time. The majority of immigrants are not from an Anglo-Saxon English speaking

D. W. L. Lai $(\bowtie)$

Faculty of Social Work, University of Calgary, 2500 University Drive, NW, Calgary, Alberta, Canada T2N1N4

e-mail: dlai@ucalgary.ca 
background. As a result, the cultural diversity of this country is becoming more obvious. For example, the percentage of visible minorities who are non-white in skin colour, nonCaucasian in race, and non-Aboriginal has risen from $4.7 \%$ in 1981 to $11.2 \%$ in 1996 , to $13.4 \%$ in 2001, and to $16.2 \%$ in 2006 (Statistics Canada 2008). With the growth of a culturally diverse population, there has been an increased interest in research to examine how the culture and ethnicity of people, particularly immigrants, influences various aspects of living in western societies. One area of research interest is ethnic identity, which is highly related to how people see themselves in the context of their own culture as well the major mainstream majority culture.

Ethnic identity refers to how individuals locate themselves psychologically in relation to social systems, based on their ethnic origin (Dickson and Timble 2005; Isajiw 1990; Phinney and Ong 2007). There are two aspects of ethnic identity that can be distinguished (Isajiw 1990). External aspects include observable behaviours such as maintaining ethnic traditions, speaking an ethnic language, and taking part in ethnic personal networks, organizations, and functions sponsored by ethnic communities. Internal aspects differ as they refer to feelings, self-perceived images, and attitudes that people hold (Isajiw 1990).

An interest in understanding different cultural backgrounds is one result of the diverse worldviews, values, beliefs, norms, and practices that people bring when they come to Canada. However, previous research studies on ethnic identity often take a strong interest in children, adolescents, and youth (Bagley et al. 2001; Cislo 2008; French et al. 2000; Wissink et al. 2008; Yon 2000). Such a strong focus on the ethnic identity of the younger generation has almost created a perception that ethnic identity is only important to this age cohort. An attempt has been made by the author to identify the recent studies on ethnicity identity of the aging population. There have been some older studies on this topic (Cool 1981; Gee 1999; Glicksman and Koropeckyj-Cox 2009; van Dijk 2004). However, in recent years, there are relatively few studies that focus on the elderly, despite the fact that cultural diversity is a reality facing the aging cohort of Canada's population.

For many people, particularly immigrants who have moved to a country with a dominant culture that is different from their own, ethnic identity determines who an individual is and what an individual wants to be in their social and cultural context. Some of the older research studies have shown that a strong sense of ethnic identity is associated with a positive selfconcept, self-efficacy, and helpful coping styles (Cislo 2008; Karlsen and Nazroo 2002; Phinney 1992; Phinney and Chavira 1995; Mossakowski 2003; Roehling et al. 2010; Smith et al. 1999; Umaña-Taylor et al. 2002). As seen from these studies, ethnic identity can affect many areas of a person's life. As such, the implications of how this concept affects people needs to be carefully researched.

The conceptual focus of ethnic identity is usually around understanding how group members understand and interpret their own ethnicity (Phinney 1993; Phinney and Baldelomar 2011; Phinney and Ong 2007). The range of ethnic identity usually represents the degree of variation in how individuals identify with their ascribed ethnic group and the extent to which their group identity is salient and significant to them. Ethnic identity is therefore seen as a continuum in which some would have a clear sense of commitment to their group while others may feel confused and conflicted about their ethnicity. While some may have a more positive emotional tie to their own people, others may wish to belong to a different group (Phinney 1993, p.66).

Back in 1970, Glazer and Moynihan (1970) were some of the earliest researchers to examine ethnicity, noting that ethnicity serves to mobilize groups to work towards interests relevant to their socioeconomic position within mainstream society. In the 1990s, ethnicity was identified as a powerful determinant in the development of 
identity and serves basic psychological needs, such as the sense of belonging and of historical continuity (McGoldrick et al. 1996); and ethnic identity was usually measured by asking participants about their self-classified ethnicity (Gee 1999; Phinney and Ong 2007). This refers to their membership in a specific ethno-cultural group on the basis of country of origin, language, religion, or cultural traditions, different from the dominant society (Hutchison 1988; Dickson and Timble 2005).

\section{Ethnicity and aging}

The role of ethnicity in explaining aging, as noted by Gee (1999), has been inconclusive. On one hand, the "ethnicity as deprivation" view considers that the ethnicity of older people may intensify the problems that they are faced with, particularly in the context of social and structural inequalities (Gee 1999; Sokolovksy 1985). The implication of this perspective means that for older people, the more they adhere to their own ethnicity, which often represents cultural values and beliefs that are different from the "mainstream majority," the more challenges they may face. This perspective echoes the 30-years old "doublejeopardy hypothesis," which considers that the disadvantaged status of being old is often aggravated by one's membership to an ethnic minority group (Dowd and Bengtson 1978). On the other hand, ethnicity can also be seen as "compensation" that provides resources to older people by maintaining one's ethnic identity and ethnic networks, and assists with adjustments and challenges (Cool 1981; Gee 1999; Karlsen and Nazroo 2002; Sokolovksy 1985; van Dijk 2004).

Some research findings tend to refute the double-jeopardy hypothesis as findings show that membership to an ethnic minority group is not essentially detrimental to the well being of an older person (Carreon and Noymer 2011; Ferraro and Farmer 1996; Simic 1993). Some researchers have begun to examine the relationships between ethnic identity and aging and found that ethnicity and culture can influence the family life of aging members and intergenerational strain in families (Johnson 1995; Lai et al. 2007; Mitchell 2003). Research has sought to analyze ethno-cultural diversity and intergenerational support, and to highlight factors that determine the attitudes of caregivers towards sharing a home with their elderly family members (Lai 2007; Mitchell 2003; Thornton and White-Means 2000).

Ethnic identity is also an important variable in health promotion and care for the elderly. A few studies report on the impact of ethnicity on the adjustment of nursing home residents (Sasson 2001; Wilson and Billones 1994). Ethnic behavior was found to be the only ethnic identity measure that was significantly associated with long term care residents' positive adjustment and satisfaction (Sasson 2001). Another study reported the importance of understanding differences in cultural heritage that cannot be ignored by those who care for new elderly immigrants (Wilson and Billones 1994).

Factors affecting health care service utilization by minority elderly were also studied, including those from African American, Asian/Pacific American, and Latino American backgrounds (Damron-Rodriguez et al. 1994; Lai 2004; Lai and Chau 2007; Lai and Surood 2010; Surood and Lai 2010; Sadavoy et al. 2004). As culture affects how one perceives and defines the meaning of illness, findings show the importance of cultural heritage knowledge to assess the unique health needs of the individual. In turn, the way in which one defines the meaning of an illness will influence the expectations of both caregivers and clients within the nurse-client relationship. As such, broadening one's understanding of a culturally diverse population is central to the concept of trans-cultural nursing (Wilson and Billones 1994). Research has shown that services need to be suited to ethnic elders' levels of functioning and congruent with ethnic expectations (Damron-Rodriguez et al. 1994; Lai and Surood 2010; Surood and Lai 2010 ). As 
the number of elderly immigrants from different cultural background continues to grow, in addition to the significant amount of elderly people of mixed heritage and cultural backgrounds, an understanding of the factors influencing ethnic identity and identification is important (Jackson and Chapleski 2000; Lai et al. 2007; Tashiro 1999) and has therefore become of the focus of this study.

This current study has three objectives: (1) to validate the factor structure of a Chinese ethnic identity measure for older Chinese in Canada, (2) to examine the level of ethnic identity of the participants, and (3) to examine the correlates of variations in ethnic identity among these older individuals. There are three reasons for this study to address the ethnic identity of older Chinese. The Chinese belong to the largest visible minority group in Canada with a total population of slightly over one million in 2001, a major increase from 860,150 in 1996. Secondly, the unique cultural characteristics and the strong traditional values that many Chinese immigrants are believed to adhere towards provides a good example for examining the role of ethnic identity in this group. As well, the recent growth of the elderly population in this ethnic group was quite significant, from $8.8 \%$ in 1996 to almost $10 \%$ in 2001. Although a previous research study attempted to examine the ethnic identity of older Chinese (Gee 1999), it failed to capture the range of ethnic identity within this target group other than relying on asking the participants to self-classify their ethnic group membership.

\section{Methods}

Data on ethnic identity of the participants for this study was obtained in an earlier study on health and well being of older Chinese adults in Canada (Lai et al. 2007). This original project was conducted between summer 2001 and spring 2002 in seven major Canadian cities-Victoria, Vancouver, Calgary, Edmonton, Winnipeg, Toronto, and Montreal. Telephone numbers listed with a Chinese surname in local telephone directories were identified to form the sampling frame. A total of 297,064 Chinese surname listings were identified. A random sample of the telephone numbers was selected based on the size of the Chinese-Canadian population and the estimated proportion of the population 55 years of age and older in each location. Using the randomly selected telephone numbers, contacts were made to identify eligible participants who were ethnic Chinese 55 years and older. As a result, a total of 40,654 numbers listed under 876 Chinese surnames were randomly selected. For telephone contacts that identified more than one eligible participant, only one was randomly selected through a roll of the dice. From these numbers, a total of 2,949 eligible participants were identified and a total of 2,272 completed the face-to-face interview, a response rate of $77 \%$.

In the study, the participants were invited to take part in a face-to-face interview to answer an orally administered structured questionnaire which consisted of questions on a wide range of health and well being topics including health status, health beliefs, cultural values, life satisfaction, and health and community service utilizations. Except for the standardized instruments that have been validated in Chinese language, all the questions were constructed in Chinese, translated into English, and translated back into Chinese to ensure that both versions were accurate and consistent in meaning. The interview was conducted in English or a Chinese dialect spoken by the participants.

Due to multi-site nature and scale of the study, community interviewers with a postsecondary education qualification, fluent in both English and one of the Chinese dialects (i.e. 
Mandarin, Cantonese and Taishan) were hired locally from each of the seven data collection sites to conduct the interviews. The interviewers were mainly graduate students in social science or human service disciplines or community interviewers who had experience in conducting survey interviews in the Chinese community. A full day face-to-face group training session, covering the skills of conducting interviews with Chinese older adults, obtaining informed consent, administering of the questionnaire, and role play was provided to all the interviewers by the research team members in each of the data collection sites. Data collection was mainly conducted in a one of the major Chinese languages (97\%) including Cantonese, Mandarin, Taishan, and Taiwanese. Since the questionnaire had gone through the forward-backward translation process to ensure consistency when being used, meanings of the questions asked were expected to be consistent despite of the type of language used in the interview. Due to the fact that an overwhelming majority (97\%) of the interviews were completed in Chinese languages, statistical comparison of the responses with the ones provided by participants who completed the questionnaire in English (3\%) was infeasible.

\section{Study variables}

Only variables that were related to the research questions examined in this study were included in the current analysis. Previous research studies on ethnic identity often asked the participants to identify themselves according to ethnic group or nationality membership (Gee 1999). This method would probably fail to address some of the embedded characteristics of ethnic identity. In this study, a Chinese Ethnic Identity Index consisting of ten items was constructed to measure the range of ethnic identity of participants. The construction of these items was based on the conceptualization of ethnic identity by Isajiw (1990) who posited that ethnic identity can be reflected through observable behaviors as well as self-perceived feelings and attitudes. Feedback from community professionals who had the experience of working with the Chinese community were also captured when constructing specific items that represent both the behavior and affect aspects of ethnic identity. The resulting items consisted of questions measuring the participants' associations and linkages with the Chinese community and peers. Some measured the frequency of participation in activities associated with the Chinese culture or community such as having Chinese food associated with Chinese festivities, listening to Chinese radio broadcasts or watching Chinese television programs, reading Chinese printed media, attending social functions organized by the Chinese community, and visiting one's place of origin. One question specifically measured the participants' self-rated importance of Chinese culture. In addition, the participants were also asked to indicate their own identity as either 'Canadian,' 'Chinese-Canadian,' or 'Chinese.'

Since the score assigned to the response in each question was different, standardized Zscores were used in calculating the total score of ethnic identity. All the item scores were transformed into Z-scores. To calculate the overall ethnic identity score, the standardized scores of all the items were summed.

To achieve the objectives of this study, a few demographic variables including gender, age, marital status, religion, education, self-rated English competency, country of origin, length of residency in Canada, self-rated financial adequacy, personal monthly income, and city of residency were included in the analysis. Gender was grouped into male and female. Age referred to the chronological age of the participants. Marital status was grouped as married, never married, divorced, and widowed. Religion was grouped into not having a religion, having a Western religion, and having a non-Western religion. Education level was grouped into four groups ranging from 'no formal education' to 'post-secondary and above.' 
Self-rated English competency was assessed using two questions asking the participants whether they were able to understand and speak English, from 'very well', 'a little bit', to 'not at all'. Scores were assigned to the answers and a higher sum represented a higher level of English competency. Country of origin referred to the country from which the participants immigrated. For those who were born in Canada, the country of origin would be Canada. Length of residency referred to the total number of years that the participants had lived in Canada. Self-rated financial adequacy was measured by asking the participants to indicate how well their income and investments satisfied their financial needs. Participants rated their financial adequacy as 'very inadequate', 'not very well', 'adequate', or 'very well', with corresponding scores of 1, 2, 3, or 4 respectively. A higher score represented a higher level of financial adequacy. Personal monthly income of the participants was grouped into 'less than $\$ 500$,' ' $\$ 500$ to $\$ 999$,' ' $\$ 1,000$ to $\$ 1,499$ ', and ' $\$ 1,500$ and above.' City of residency referred to the city in which the participants resided at the time this study was conducted.

Data analysis

Descriptive statistics including frequency distributions and means were used to present the demographic information of the participants. To identify the underlying factor structure of the Chinese Ethnic Identify Index, exploratory factor analysis using principal component analysis was conducted, with half the sample that was randomly assigned into the two groups. Using the other half of the sample, confirmatory factor analysis was also conducted to examine whether the initial factor structure identified in exploratory factor analysis achieved a goodness-of-fit with the data and significance of individual factor loadings. Based on the resulting factors identified, Ordinary Least Square (OLS) multiple stepwise regression analysis was performed to examine the correlates of ethnic identity of the older Chinese, using each of the ethnic identity factors as the dependent variable respectively, using the full sample again.

\section{Results}

Table 1 presents the demographic information of the older Chinese who took part in this study. Although the participants were all ethnic Chinese, the findings indicated that they belonged to a diverse group with different countries of origin and length of residency in Canada. A brief summary of the demographic characteristics of the participants is presented in Table 1.

The standardized ethnic identity scores ranged from -18.49 to 12.04 , with a standardized mean of zero $(\mathrm{sd}=4.59)$. However, the internal consistency of the scale was very moderate, with a Cronbach's alpha coefficient of 0.58 that was not modified by removal of any items. This also reflected the possibility that the concept of ethnic identity was not onedimensional, which further justified the need for examining the factor structure embedded in these items.

Principal component analysis was used to explore the initial factor structure of the 10 items constructed for measuring the ethnic identity of older Chinese, using half of the sample $(n=1,136)$. The finding revealed that the ten items were made up of four unrotated factors with eignevalues greater than one accounting for $58.71 \%$ of the variance in the scale. This percentage, though not really high, is considered to be within the acceptable range as indicated by experts of factor analysis (Streiner 1994). Among the four factors, the first factor accounted for $22.83 \%$ while the second and third factors accounted for additional 
Table 1 Demographics of the participants $(N=2,272)$

Gender (\%)

Age (in yrs), mean (SD)

Marital status (\%)

Religion (\%)

Education (\%)

Self-rated English competency, mean (SD)

(Range: 2-6)

Country of origin $(\%)$

Length of residency (yrs), mean (SD)

Self-rated financial adequacy, mean (SD)

(Range: 1-4)

Personal monthly income (\%)

City of residency $(\%)$
Female

55.8

Male

44.2

$69.8(8.7)$

66.0

Married

1.4

Never married

1.9

Divorced/Separated

28.4

Widowed

66.0

Married

42.1

Not having a religion

26.9

Having a western-religion

30.9

Having a non-western religion

12.7

Elementary

28.3

Secondary

37.8

Post sec. \& above

21.1

Born in Canada $\quad 1.6$

Mainland China $\quad 27.1$

Hong Kong

51.1

Taiwan

4.4

Vietnam

7.9

Southeast Asia

4.0

Other countries

$19.0(13.7)$

$2.8(.6)$

Less than $\$ 500$

\$500-\$999

38.0

$\$ 1,000-\$ 1,499$

34.2

$\$ 1,500$ \& above

11.4

Victoria

11.0

Greater Vancouver

22.6

Calgary

12.2

Edmonton

13.9

Winnipeg

5.0

Greater Toronto

24.3

Greater Montreal

variability of $14.27 \%$ and $11.00 \%$ respectively. The final factor accounted for $10.61 \%$ of the variance in the scale. The use of both the varimax and oblimin rotations with Kaiser Normalization indicated that the four factors extracted are exactly the same. The factor loadings after the varimax rotation are presented in Table 2. These three factors are related to: (1) culture related activities - listening to Chinese radio broadcasts or watching Chinese television programs, reading Chinese newspapers, magazines, or other periodicals, eating 
Table 2 Results of exploratory factor analysis $(n=1,136)$

\begin{tabular}{|c|c|c|c|c|}
\hline & $\begin{array}{l}\text { Factor } 1: \text { Culture } \\
\text { related activities }\end{array}$ & $\begin{array}{l}\text { Factor 2: } \\
\text { Community } \\
\text { ties }\end{array}$ & $\begin{array}{l}\text { Factor } 3 \text { : Linkage } \\
\text { with country of } \\
\text { origin }\end{array}$ & $\begin{array}{l}\text { Factor 4: } \\
\text { Cultural } \\
\text { identification }\end{array}$ \\
\hline $\begin{array}{l}\text { Listen to Chinese radio broadcasts } \\
\text { or watch Chinese television } \\
\text { programs }\end{array}$ & .787 & & & \\
\hline $\begin{array}{l}\text { Read Chinese newspapers, } \\
\text { magazines, or other periodicals }\end{array}$ & 649 & & & \\
\hline Number of close friends are Chinese & .572 & & & \\
\hline $\begin{array}{l}\text { Eat food associated with Chinese } \\
\text { holidays or special events }\end{array}$ & .412 & & & \\
\hline $\begin{array}{l}\text { Tie with the Chinese community in } \\
\text { Canada }\end{array}$ & & .866 & & \\
\hline Attend Chinese social functions & & .833 & & \\
\hline Visit Asia & & & .856 & \\
\hline Visit place of origin & & & .850 & \\
\hline National identity & & & & .821 \\
\hline Importance of Chinese culture & & & & .656 \\
\hline
\end{tabular}

Extraction Method: Principal Component Analysis

Rotation Method: Varimax with Kaiser Normalization, rotation converged in six iterations

food that is associated with Chinese holidays or special events, and having a number of close friends who are Chinese, (2) community ties - ties with the Chinese community in Canada, and attending Chinese social functions, (3) linkage with country of origin-visiting their place of origin, and visiting Asia, and (4) cultural identification.

Among the four factors identified, since the three factors related to linkage with country of origin, community ties, and cultural identification were represented by only two observed variables, an alternative exploratory factor analysis was conducted by limiting the extraction to form a three-factor model hoping that at least three observed variables could be loaded to each of the factors to meet the minimal requirement (Streiner 1994). However, the resulting three-factor model based upon these ten observed variables yielded a much less desirable result with only $48.63 \%$ of the variance in the scale explained. Therefore, the four-factor was finally adopted despite of its limitation of having factors consisting of only two indicators.

Using LISREL 8.72, maximum-likelihood confirmatory factor analysis was conducted to assess the generalizability of the four-factor model that emerged in the Principal Component Analysis, based on another half of the sample $(n=1,136)$. Evaluation criteria used to judge adequacy of the model included: the goodness-of-fit (GFI, values greater than .90), the adjusted goodness-of-fit (AGFI, values greater than .80), and the root mean square residual (RMR, values less than .20). The GFI $=.99$, the $A G F I=.97$, and the $\mathrm{RMR}=.03$ values for the four-factor model in this study indicated a rather good fit between the model and the observed data. The loadings of the items to each the factors are presented in Fig. 1.

The correlates also need to be examined using each of the four factors as the dependent variable respectively. Table 3 presents the stepwise multiple regression models, using the standardized factor score for each of four ethnic identity factors as the dependent variable respectively. The correlates entered into each set of regression analysis included: gender, age, marital status, religion, education, self-rated English competency, country of origin, length of residency in Canada, self-rated financial adequacy, personal monthly income, and 


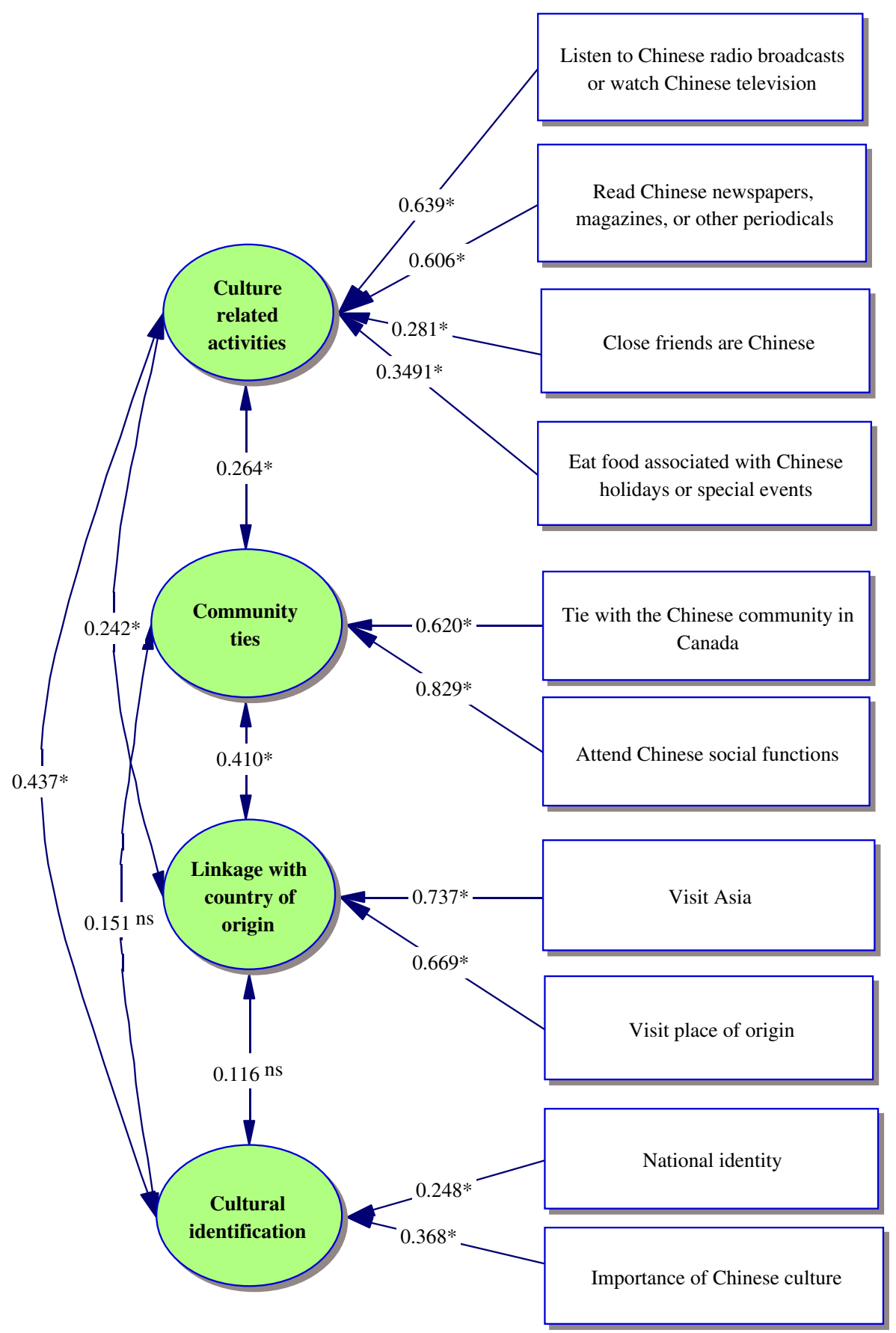

Fig. 1 Result of confirmatory factory analysis for the Chinese ethnic identity items $(n=1,136) \cdot p<.05$, ${ }^{\text {ns }}$ not significant 
Table 3 Multiple regression analysis of correlates of ethnic identity factors $(N=2,272)$

\begin{tabular}{|c|c|c|c|c|}
\hline & $\begin{array}{l}\text { Culture related } \\
\text { activities }\end{array}$ & $\begin{array}{l}\text { Community } \\
\text { ties }\end{array}$ & $\begin{array}{l}\text { Linkage with country of } \\
\text { origin }\end{array}$ & $\begin{array}{l}\text { Cultural } \\
\text { identification }\end{array}$ \\
\hline & \multicolumn{4}{|l|}{ Beta coefficients } \\
\hline Gender ${ }^{\mathrm{a}}$-Male & - & $.074 * * *$ & - & - \\
\hline Age & $.055^{*}$ & - & $-.074 * * *$ & - \\
\hline Being married $^{\mathrm{b}}$ & $.145^{* * *}$ & - & - & $-.053 * *$ \\
\hline \multicolumn{5}{|l|}{ Religion $^{c}$} \\
\hline $\begin{array}{l}\text { Having a western } \\
\text { religion }\end{array}$ & $-.052 *$ & $.120 * * *$ & - & - \\
\hline $\begin{array}{l}\text { Having a non-western } \\
\text { religion }\end{array}$ & $.067 * *$ & - & - & - \\
\hline \multicolumn{5}{|l|}{ Education $^{\mathrm{d}}$} \\
\hline Elementary & $.162 * * *$ & - & - & - \\
\hline Secondary & $.155^{* * *}$ & - & - & - \\
\hline Post sec. \& above & - & $.082 * * *$ & $.058 * *$ & $.043 * *$ \\
\hline $\begin{array}{l}\text { Self-rated English } \\
\text { competency }\end{array}$ & $.039 *$ & - & - & - \\
\hline \multicolumn{5}{|l|}{ Country of origin ${ }^{\mathrm{e}}$} \\
\hline Mainland China & $.161 * * *$ & - & $-.079 * * *$ & - \\
\hline Hong Kong & $.193 * * *$ & - & - & $-.071 *$ \\
\hline Taiwan & - & $.049 *$ & $.083 * * *$ & - \\
\hline Vietnam & - & - & - & - \\
\hline Southeast Asia & - & $-.047 *$ & $.042 *$ & $-.067 *$ \\
\hline Other countries & - & - & $.049 *$ & - \\
\hline $\begin{array}{l}\text { Length of residency } \\
\text { (yrs) }\end{array}$ & $-.261 * * *$ & $.096 * * *$ & $-.080 * * *$ & $-.162 * * *$ \\
\hline $\begin{array}{l}\text { Self-rated financial } \\
\text { adequacy }\end{array}$ & - & $.046^{*}$ & $.060 * *$ & - \\
\hline \multicolumn{5}{|c|}{ Personal monthly income ${ }^{f}$} \\
\hline$\$ 500-\$ 999$ & $.065 * *$ & - & - & $-.054 * *$ \\
\hline$\$ 1,000-\$ 1,499$ & - & - & - & - \\
\hline$\$ 1,500 \&$ above & $-.051 *$ & - & - & - \\
\hline \multicolumn{5}{|l|}{ Location $^{\mathrm{g}}$} \\
\hline Victoria & $-.048 *$ & - & - & $-.048 * *$ \\
\hline Calgary & - & - & - & - \\
\hline Edmonton & - & - & - & - \\
\hline Winnipeg & $-.049 *$ & $.059 * *$ & - & - \\
\hline Greater Toronto & - & $-.066^{* *}$ & - & $-.096 * * *$ \\
\hline Greater Montreal & $-.075^{* * *}$ & $-.128 * * *$ & $-.056 * *$ & $-.110^{* * *}$ \\
\hline$R^{2}$ & .191 & .074 & .049 & .057 \\
\hline Adjusted $R^{2}$ & .185 & .070 & .045 & .054 \\
\hline
\end{tabular}

${ }^{*} p<.05, * * p<.01, * * * p<.001$, - ${ }^{*}$ not entered into the regression equation

Reference groups: ${ }^{a}$ female; ${ }^{b}$ single (including never married, divorce or separated, and widowed); ${ }^{c}$ not having a religion; ${ }^{\mathrm{d}}$ no formal education; ${ }^{\mathrm{e}}$ born in Canada; ${ }^{\mathrm{f}}$ less than $\$ 500 ;{ }^{\mathrm{g}}$ greater Vancouver 
city of residency. Due to the fact that the proportion of participants reported to be never married and divorced/separated was very low, these two groups were grouped together with the widowed group and recoded as "single" in the regression analysis.

The results indicated that the correlates of different dimension of ethnic identity were slightly different. A higher level of participation in culture related activities correlated significantly with being younger in age, being married, having a nonwestern religion, having elementary or secondary education level, higher self-rated English competency, being an immigrant from Mainland China and Hong Kong, shorter length of residency in Canada, and having an income of $\$ 500$ to $\$ 999$. On the other hand, those who reported to have a Western religion, shorter length of residency in Canada, having an income of $\$ 1,500$ and above, residing in Victoria, Winnipeg, and Greater Montreal were the ones having a higher level of participation in culture related activities.

Having more ties to the Chinese community correlated significantly with the male gender, having a Western religion, having a post-secondary education and above, being an immigrant from Taiwan, longer a length of residency in Canada, and a better self-rated financial adequacy. On the other hand, being an immigrant from Southeast Asia and those who resided in Greater Toronto and Greater Montreal reported a lower level of community ties.

A stronger linkage with country of origin correlated significantly with having a postsecondary and above education level, being an immigrant from Taiwan, Southeast Asia, and other countries, and a higher level of self-rated financial adequacy. Those who were younger in age, from Mainland, resided in Canada for a shorter period of time, and resided in Montreal, reported a weaker linkage with country of origin.

Finally, a higher level of cultural identification correlated significantly with postsecondary education level. On the other hand, those who reported being married, being an immigrant from Hong Kong or Southeast Asia, having a shorter length of residency in Canada, having an income from $\$ 500$ to $\$ 999$, residing in Victoria, Greater Toronto, and Greater Montreal, were the ones reporting a lower level of cultural identification.

\section{Discussion}

These findings have supported the fact that the ethnic identity of older Chinese is not a singledimension construct but one with multiple dimensions. Consistent with previous research findings, the ethnic identity of the aging Chinese in Canada is manifested through observable behaviors as well as internal aspects such as feelings, self-perceived images, and attitudes that people hold (Isajiw 1990). Three of the four factors identified in this study indicate that ethnic identity as presented in the older Chinese consists of the external observable behaviors related to maintaining ethnic traditions, maintaining the use of an ethnic language, taking part in ethnic specific activities and organizations (Isajiw 1990). At the same time, consistent with previous literature (Gee 1999; Isajiw 1990), variables related to attitudes and self-perceived images that people hold were loaded to the cultural identification factor.

This study has shown that for the older Chinese, there are several aspects that represent their ethnic identity level. The four factors identified provide a better understanding of how ethnic identity can be measured. The findings supported that the sole reliance of ethnic or nationality membership as a classification tool of the older Chinese in Canada is inadequate. As indicated in findings, the virtue of ethnic identity is more than self-identification. It includes various behavioral aspects that researchers should consider when trying to understand the ethnic identity of older Chinese in Canada. 
The four-factor model identified in this study will allow future research a better approach for capturing or measuring ethnic identity. Future efforts to measure ethnic identity should at least include measures of these dimensions identified. When assessing ethnic identity of the aging Chinese, future research should attempt to capture both the subjective and objective factors of the construct, as proposed by many researchers (Isajiw 1990; Phinney 1993; Gee 1999). Most importantly, as previous research and literature have argued that maintaining one's ethnic group membership and ethnic identity would be beneficial to ethno-cultural minority older adults' adjustments (Cool 1981; Gee 1999; Karlsen and Nazroo 2002; Simic 1993; Sokolovksy 1985; van Dijk 2004), as well as other positive outcomes such as positive self-concept, self-efficacy, and helpful coping styles (Cislo 2008; Karlsen and Nazroo 2002; Phinney 1992; Phinney and Chavira 1995; Mossakowski 2003; Roehling et al. 2010; Smith et al. 1999), future research should further delineate the effects of the different subjective and behavioral dimensions of ethnic identity on adjustment and these well being variables.

It is important to note the different correlates of the various ethnic identity dimension or factors. The influence of some of the culture related variables such as country of origin, length of residency in Canada on the different ethnic identity factors also varies, depending on the specific ethnic identity dimension examined. For example, although immigrant seniors from China reported a higher level of participation in culture related activities, they reported a weaker linkage with country of origin. Being more educated and more financially adequate predicted stronger linkages and ties with country of origin in this study. The finding demonstrates the external behavioral aspect of ethnic identity as identified by Isajiw (1990). However, education and financial adequacy actually represent the social and financial resources that support the affordability of individuals to travel back to their own countries of origin. These trips are often associated with substantial financial costs. In addition, it is not uncommon for those who have lived in Canada for a shorter period of time to pay more visits to their countries of origin as a way to search for their cultural roots. As shown in the data, the intention to maintain the ties with one's country of origin is also more prevalent among those who were Canadian born. This can be explained by the fact that these individuals may have more interest in exploring their cultural roots and may be better financed to travel. Without an in-depth understanding of the underlying reasons for these visits and ties, this explanation remains speculative. Future research to explore further, probably through qualitative methods, would be useful to verify this plausible reason.

On the other hand, when ethnic identity was represented by participation in cultural activities in the Chinese community, it is the immigrants, particularly the recent ones with shorter lengths of residency in Canada, that show higher levels of identification with their Chinese ethnic identity. The role of socio-economic resources such as education and income are also facilitative to their level of participation in these community events and programs. Interestingly, better finance and higher education were also significantly correlated with the participants' stronger ties to the Chinese community.

While one may think that those who are older would probably have a stronger Chinese ethnic identity, this study has only partially supported this hypothesis. Among the older adults in this study, being older was a significant correlate of only one ethnic identity factor, which was participation in culture related activities.

When compared with the Canadian born older Chinese, immigrants from Mainland China and Hong Kong reported higher levels of participation in culture related activities, and immigrants from Taiwan reported having stronger ties with the Chinese community. These findings are consistent with the view that immigrants often maintain a higher level of ethnic identity when compared with their native born counterparts from the same ethnic background. These findings have demonstrated the cultural diversity within the same ethnic 
group. In this case, country of origin has indicated its significant impact in explaining differences in ethnic identity when being measured by different ethnic identity factors.

City of residency was a significant correlate of all four ethnic identity factors. The most apparent finding is that living in Vancouver was a significant correlate of higher levels of Chinese ethnic identity, in terms of linkages with country of origin, participation in Chinese cultural activities, and ties with the Chinese community. The findings are not surprising since it is well known that Vancouver has one of the oldest Chinese-Canadian communities and a very substantial concentration of ethnic Chinese. The well established social groups and community organizations in the Chinese community in Vancouver and associated Lower Mainland area have probably played a very significant role in providing opportunities for older Chinese to maintain strong community ties and be involved in related Chinese community activities and functions.

To conclude, the findings in this study have provided a more thorough picture of the ethnic identity of older Chinese in Canada. The four-factor model for Chinese ethnic identity reported provides a good example for researchers to better understand that both the behavioral and subjective aspects of ethnic identity should be considered. The findings have also served to demonstrate that ethnicity is a multi-dimensional concept, therefore shaping the future definition of ethnic identity within the cultural context of the aging Chinese in Canada. Based on the findings on the multi-dimensionality of the construct, ethnicity identity can be redefined in a more specific manner. Ethnic identity is more than a selfidentified social location. It is a manifestation of one's connection with and participation in the current and previous socio-cultural milieu of an individual. Like the results reported in this study, even within the same ethnic group, the level of ethnic identity reported could be influenced by differences in country of origin and other socio-demographic correlates.

The findings from this current study would serve to identify future new research directions, particularly related to examining the effects of specific aspects or domains of ethnic identity on the health and well being of aging Chinese immigrants. In the past two decades, studies have indicated that ethnic identity is a positive factor for healthy aging (Ferraro and Farmer 1996; Simic 1993), positive family life of aging adults (Mitchell 2003), and better adjustment of nursing home residents (Sasson 2001; Wilson and Billones 1994). Interestingly, the behaviors related to ethnic identity were significantly associated with positive adjustment and satisfaction (Sasson 2001). All these previous findings have shown the potential effects of ethnic identity on health and well being of the aging population. However, the specific effects of the different domains or dimensions of ethnic identity on well being outcomes were missing. Therefore, future research on ethnicity and aging should focus on how the different domains of ethnic identity of the aging Chinese affect their life satisfaction, adjustment to healthy aging, and the access and use of formal or informal services and support. It is also interesting to further examine the relative contribution or importance of the different domains of ethnic identity to the various aspects of health and well being of aging Chinese immigrants. Another aspect of research potential is to further examine the experiential aspect of ethnic identity. The use of qualitative research to capture older Chinese immigrants' inner experience and meanings of this aspect of personality is recommended.

Finally, for policy planners and service providers who agree with the positive contributions and effects of ethnic identity on the well being outcomes of ethno-cultural minority older adults, interventions and service programs can be designed to facilitate the development of ethnic identity. Although services and intervention programs may not necessarily change one's subjective aspect of ethnic identity directly, strengthening or facilitating the opportunities for social ties and connections within one's ethno-cultural community could be useful for the development of a stronger ethnic identity, which has been found to carry positive effects for the ethno-cultural minority older adults. 
Acknowledgements This research was funded by the Social Sciences and Humanities Research Council under the Strategic Theme: Society, Culture and Health of Canadians (Grant No: 828-1999-1032).

Open Access This article is distributed under the terms of the Creative Commons Attribution Noncommercial License which permits any noncommercial use, distribution, and reproduction in any medium, provided the original author(s) and source are credited.

\section{References}

Bagley, C., Bolitho, F., \& Bertrand, L. (2001). Ethnicities and social adjustment in Canadian Adolescents. International Journal of Migration and Integration, 2(1), 99-119.

Carreon, D., \& Noymer, A. (2011). Health-related quality of life in older adults: testing the double jeopardy hypothesis. Journal of Aging Studies, 25, 371-379.

Cislo, A. M. (2008). Ethnic identity and self-esteem: contrasting Cuban and Nicaraguan young adults. Hispanic Journal of Behavioral Sciences, 30(2), 230-250.

Cool, L. E. (1981). Ethnic identity: a source of community esteem for the elderly. Anthropological Quarterly, $54,179-189$.

Damron-Rodriguez, J., Wallace, S., \& Kington, R. (1994). Service utilization and minority elderly: appropriateness, accessibility and acceptability. Gerontology \& Geriatrics Education, 15(1), 45-63.

Dickson, R., \& Timble, J. E. (2005). Ethnic identity. In C. B. Fisher \& R. M. Lerner (Eds.), Encyclopedia of applied developmental science, vol. 1 (pp. 415-420). Thousand Oaks: Sage.

Dowd, J. J., \& Bengtson, V. L. (1978). Aging in minority populations: an examination of the double jeopardy hypothesis. Journal of Gerontology, 33(3), 427-436.

Ferraro, \& Farmer. (1996). K.F Ferraro and M.M Farmer, Double jeopardy to health hypothesis for African Americans. Journal of Health and Social Behavior, 37, 27-43.

French, S. E., Seidman, E., Allen, L., \& Lawrence, A. (2000). Racial/ethnic identity, congruence with the social context, and the transition to high school. Journal of Adolescent Research, 15(5), 587-602.

Gee, E. M. (1999). Ethnic identity among foreign-born Chinese Canadian elders. Canadian Journal on Aging, 18(4), 415-429.

Glazer, N., \& Moynihan, P. (1970). Beyond the melting pot. Cambridge: MIT Press.

Glicksman, A., \& Koropeckyj-Cox, T. (2009). Aging among Jewish Americans: implications for understanding religion, ethnicity, and service needs. The Gerontologist, 49(6), 816-827.

Hutchison, R. (1988). A critique of race, ethnicity, and social class in recent leisure recreation research. Journal of Leisure Research, 20, 10-30.

Isajiw, W. W. (1990). Ethnic-identity retention. In W. W. Isajiw (Ed.), Ethnic identity and equality. Toronto: University of Toronto Press.

Jackson, D., \& Chapleski, E. (2000). Not traditional, not assimilated: elderly American Indians and the notion of 'cohort'. Journal of Cross Cultural Gerontology, 15(3), 229-259.

Johnson, T. W. (1995). Utilizing culture in work with aging families. Strengthening aging families: diversity in practice and policy. Thousand Oaks: Sage.

Karlsen, S., \& Nazroo, J. Y. (2002). Agency and Structure: the impact of ethnic identity and racism on the health of ethnic minority people. Sociology of Health \& Illness, 24, 1-20.

Lai, D. W. L. (2004). Use of home care services by elderly Chinese immigrants. Home Health Care Services Quarterly, 23, 41-56.

Lai, D. W. L. (2007). Cultural predictors of caregiving burden of Chinese-Canadian family caregivers. Canadian Journal on Aging, 26(suppl.1), 133-148.

Lai, D. W. L., \& Chau, S. B. Y. (2007). Predictors of health service barriers for older Chinese immigrants in Canada. Health and Social Work., 32(1), 57-65.

Lai, D. W. L., \& Surood, S. (2010). Types and factor structure of barriers to utilization of health services among aging South Asians in Calgary, Canada. Canadian Journal on Aging, 29(2), 249-258.

Lai, D. W. L., Tsang, K. T., Chappell, N. L., Lai, D. C. Y., \& Chau, S. B. Y. (2007). Relationships between culture and health status: a multi-site study on older Chinese in Canada. Canadian Journal on Aging, 26(3), 171-184.

McGoldrick, M., Giordano, J., \& Pearce, J. K. (Eds.). (1996). Ethnicity and family therapy (2nd ed.). New York: Guilford.

Mitchell, B. A. (2003). Would I share a home with an elderly parent? Exploring ethnocultural diversity and intergenerational support relations during young adulthood. Canadian Journal on Aging, 22(1), 69-82.

Mossakowski, K. N. (2003). Coping with perceived discrimination: does ethnic identity protect mental health? Journal of Health and Social Behavior, 44, 318-331. 
Phinney, J. S. (1992). The multigroup ethnic identity measure. Journal of Adolescent Research, 7(2), 156176.

Phinney, J. (1993). A three-stage model of ethnic identity development. In M. Bernal \& G. Knight (Eds.), Ethnic identity: formation and transmission among Hispanics and other minorities. Albany: State University of New York Press.

Phinney, J. S., \& Baldelomar, O. A. (2011). Identity development in multiple cultural contests. In L. A. Jensen (Ed.), Bridging cultural and developmental approaches to psychology: New syntheses (pp.161-pp.186). Oxford University Press.

Phinney, J. S., \& Chavira, V. (1995). Parental ethnic socialization and adolescent coping with problems related to ethnicity. Journal of Research on Adolescence, 5(1), 31-53.

Phinney, J. S., \& Ong, A. D. (2007). Conceptualization and measurement of ethnic identity: current status and future directions. Journal of Counseling Psychology, 54, 271-281.

Roehling, P. V., Jarvis, L. H., Sprik, J. M., \& Campbell, P. H. (2010). The immigration debate and its relationship to the ethnic identity development and well-being of Latino and White Youth. Hispanic Journal of Behavioral Sciences, 32(2), 292-308.

Sadavoy, J., Meier, R., \& Ong, A. (2004). Barriers to access to mental health services for ethnic seniors: the Toronto study. Canadian Journal of Psychiatry, 49, 192-199.

Sasson, S. (2001). The impact of ethnic identity upon the adjustment and satisfaction of Jewish and African American residents in a long-term care facility. Social Work in Health Care, 33(2), 89104.

Simic, A. (1993). Aging and ethnic identity: a refutation of the double-jeopardy theory. Journal of Case Management, 2(1), 9-13.

Smith, E. P., Walker, K., Fields, L., Brookins, C. C., \& Seay, R. C. (1999). Ethnic identity and its relationship to self-esteem, perceived efficacy and prosocial attitudes in early adolescence. Journal of Adolescence, $22,867-880$.

Sokolovksy, J. (1985). Ethnicity, culture and aging: do differences really make a difference? Journal of Applied Gerontology, 4, 6-17.

Statistics Canada. (2007). Immigration in Canada: A portrait of the foreign-born population, 2006 Census. Catalogue no. 97-557-XIE. Ottawa. http://www12.statcan.ca/census-recensement/2006/as-sa/97-557/pdf/ 97-557-XIE2006001.pdf. (Accessed November 9, 2011)

Statistics Canada. (2008). 2006 Census: ethnic origin, visible minorities, place of work and mode of transportation. The Daily, April 2, 2008. Ottawa. http://www.statcan.gc.ca/daily-quotidien/080402/ dq080402a-eng.htm. (Accessed November 9, 2011)

Streiner, D. L. (1994). Figuring out factors: the use and misuse of factor analysis. Canadian Journal of Psychiatry, 39(3), 135-40.

Surood, S., \& Lai, D. W. L. (2010). Impact of culture on use of western health services by older South Asian Canadians. Canadian Journal of Public Health, 101(2), 176-80.

Tashiro, C. J. (1999). Standing on both feet: History and the construction of identity for older mixed-race Americans. (elderly). Dissertation Abstracts International, 60(4-A).

Thornton, M. C., \& White-Means, S. I. (2000). Race versus ethnic heritage in models of family economic decisions. Journal of Family \& Economic Issues, 21(1), 65-86.

Umaña-Taylor, A., Diversi, M., \& Fine, M. A. (2002). Ethnic identity and self-esteem of Latino adolescents: distinctions among Latino populations. Journal of Adolescent Research, 17, 303-327.

van Dijk, J. V. (2004). The role of ethnicity and religion in the social support system of older Dutch Canadians. Canadian Journal on Aging, 23(1), 21-34.

Wilson, S., \& Billones, H. (1994). The Filipino elder: implications for nursing practice-knowledge of heritage essential. Journal of Gerontological Nursing, 20(8), 31-6.

Wissink, I. B., Dekovic, M., Yagmur, S., Stams, G. J., \& de Haan, M. (2008). Ethnic identity, externalizing problem behavior and the mediating role of self-esteem among Dutch, Turkish-Dutch and MoroccanDutch adolescents. Journal of Adolescence, 31(2), 223-240.

Yon, D. A. (2000). Urban portraits of identity: on the problem of knowing culture and identity in intercultural studies. Journal of Intercultural Studies, 21(2), 143-157. 